\title{
Forecasting of Sporadic Products: Practical and Theoretical Considerations
}

\author{
Andrea Gelei ${ }^{1}$ Imre Dobos ${ }^{2 *}$ \\ ${ }^{1}$ Department of Logistics and Supply Chain Management, Corvinus University of Budapest, Fővám tér 8., 1093 Budapest, Hungary \\ 2 Department of Economics, Faculty of Economic and Social Sciences, Budapest University of Technology and Economics, \\ 1111 Budapest, Hungary, Magyar Tudósok Körútja 3, Q épület \\ * Corresponding author, e-mail: dobos@kgt.bme.hu
}

Received: 20 September 2018, Accepted: 22 February 2019, Published online: 30 April 2020

\begin{abstract}
This paper focuses on forecasting of products with sporadic demand. The demand for such products is not continuous but diffused seemingly at random, with a large proportion of zero values in the analyzed time series. The sporadic character of demand patterns actually means that the information available on the demand for previous selling periods is patchy, resulting in lower quality of data available. Under such circumstances demand forecasting is a challenging task. We present the results of a case study, where forecasting practice of a pharmaceutical wholesaler firm -we call it Pharma- is analyzed and developed. We present state-of-the-art knowledge related to demand forecasting of sporadic products and test suggestions related to them. We show that these suggestions can only partly be backed. We extend therefore the suggested product classification scheme and recommend using the concept of demand data aggregation. This will reduce sporadicity and result in higher quality forecasting. Aggregation also helps to specify the recommended forecast period, the length of time recommended to calculate the forecast for. The managerial consequences of these suggestions are also discussed, and future research directions are highlighted.
\end{abstract}

\section{Keywords}

forecasting, sporadic demand, classification scheme, case study

\section{Introduction}

Inventory management and forecasting are traditionally linked to each other and represent a major research area in operations and logistics management. Although interest in the topic is long-standing, research in the field has intensified recently due to previously neglected though, now increasingly important new aspects of demand characteristics. One of these new aspects is the sporadic nature of demand, which is the focus of this paper. Demand for some products (or services) is not continual in time; its demand is diffused and random with a large proportion of zero values in the analyzed time series (Chitturi et al., 2010; Jónás et al., 2018; Petropoulos and Kourentzes, 2015). The quality of previous data about demand on which forecasting is built has always been treated as a crucial point in forecasting. The sporadic character of demand patterns actually means that the information available on the demand of previous selling periods is patchy, resulting in lower quality data. Under such circumstances demand forecasting is a challenging task.
Sporadic demand has previously been researched mainly in connection with forecasting components and service parts (Croston, 1972; Eaves and Kingsman, 2004; Pennings et al., 2017; Vasumathi and Saradha, 2014). Recently the topic has again become prominent but now related to "traditional" products and services, such as pharmaceuticals. The forecasting problems of this industry are analysed in this paper. The product portfolio of a wholesale firm of pharmaceutical products is empirically analyzed in this context. The company -we call it Pharma- is an actual firm which wished to remain anonymous and serves as a case for our analysis.

Investigating the phenomena of sporadic demand is relevant from a managerial perspective because it can increase operational effectiveness and efficiency. New forecasting methods considering the sporadic nature of demand have been developed and proposed which promise a higher forecast accuracy and thus an improved level of service with lower inventory investment (Babiloni et al., 2010; 
Chitturi et al., 2010; Kourentzes, 2014). The objective of our paper is to empirically test these newly developed methods and their efficacy. According to our analysis based on long term and real-life time series data, it was found that the new methods proposed really can lead to higher forecast accuracy in certain cases, when basic (daily) demand data is aggregated in time. This aggregation allows an appropriate forecasting period to be determined (working days, weeks, months or even quarters).

This paper presents a business application of forecasting methods developed to help Pharma improve its performance. However, as will be discussed in the paper, our application- oriented work has resulted in new observations, given us new insights and resulted in generalizable suggestions related to the state-of-the-art knowledge in this field. These new insights also raise new questions and open new research directions in the field of forecasting and inventory management.

\section{Forecasting of sporadic demand}

The key feature of demand patterns investigated in our paper is sporadicity. When sporadicity is analyzed, the distribution of periods during a given analytical timeframe (e.g. days over one year) with no demand for a product is compared with the distribution of periods when there is demand. The index of sporadicity actually indicates the average length and consequently also the proportion of periods without demand in the timeframe studied. The demand for a product is said to be sporadic when the average length and/or the proportion of periods with 0 demand in a given timeframe is relatively high. There is no generally accepted value, only some rules for determining sporadicity (Croston, 1972).

In order to be able to carry out high quality forecasting and chose the appropriate forecasting method, it is important to conduct an in-depth analysis of demand data from previous selling periods and acquire a deep understanding of the product's demand pattern. Traditionally the coefficient of demand volume variation was the basic feature forecasting focused on and on which the selection of suitable forecast method was based (Peterson and Silver, 1985; Vollman et al., 1984). This coefficient of demand volume variation is defined as follows,

$$
C V_{D E}=\frac{D(X)}{E(X)}
$$

where $D(X)$ is the standard deviation of the probability variable $X$-in our case this is the actual demand for a product for the forecast period-while $E(X)$ is its expected value. Some of the authors suggest 0.45 as the threshold value for the coefficient of demand volume variation (Peterson and Silver, 1985). Others place the value higher, at 0.7 (Boylan et al., 2008).

As highlighted above, the coefficient of variation is not the only relevant demand characteristic. In order to be able to analyze the sporadicity of demand, the average interdemand interval $(p)$ is also used in forecasting (Syntetos and Boylan, 2001).

Employing these two key demand pattern characteristics, Boylan et al. (2008) developed a classification scheme of products. Products with low demand volume variation and low sporadicity index (that is low expected proportion of demand periods with 0 demand in the analyzed timeframe that is the $p$ ) are called smooth products. When a demand volume variation of a product is low, but its sporadicity index is high, it is known as an intermittent demand item. Products that are characterized by high demand volume variation but for which demand is not highly sporadic, are categorized as erratic. Where both demand volume variation and sporadicity are high, the product category is labelled as lumpy (see Fig. 1). As mentioned, Boylan and his co- authors suggest 0.7 as a threshold value for demand volume variation, while 1.32 is used as the threshold for average interdemand interval. These threshold values are used in the present study.

Two relatively new methods have been developed and published that take into consideration the effect of sporadicity, the Croston method and the Syntetos-Boylan method (Syntetos et al., 2005). The Croston method is a version of the simple exponential smoothing modified and extended for products with high sporadicity. Its core idea is to calculate the number of periods with 0 demand in the analyzed timeframe and build in an additional smoothing equation. The mathematical-statistical description

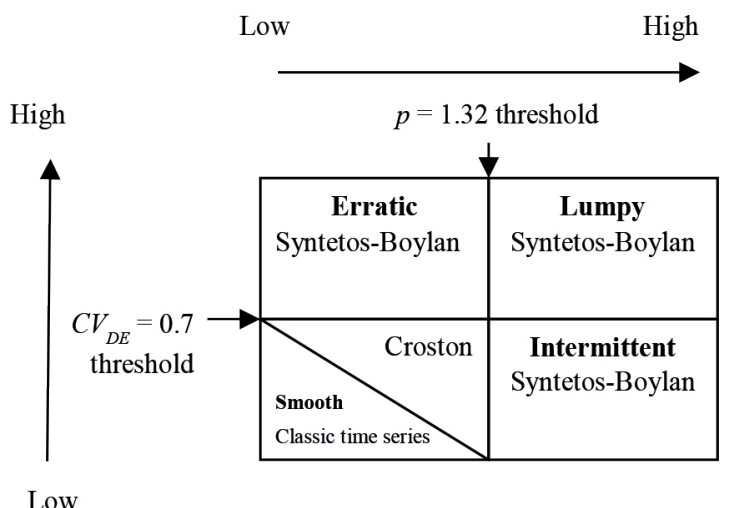

Fig. 1 Recommended forecast methods according to demand volume variation and sporadicity (Babiloni et al., 2010; Boylan et al., 2008) 
can be found in the work of Croston published in 1972 . Syntetos and Boylan have pointed out, however, that the Croston method results in biased estimation. They developed the Boylan-Syntetos method, which is based on the Croston method but which should result in an unbiased forecast. A detailed description of this latter method is presented in Syntetos and Boylan (2001).

According to Boylan et al. (2008) and Babiloni et al. (2010) different product categories require different forecasting methods to be used. Where demand volume variation (that is $C V_{D E}$ ) is over 0.7 and/or the sporadicity of a product are high (value of $p$ is higher than 1.32), the recommended forecasting method is the Syntetos-Boylan method. For products with low coefficient of variation $\left(C V_{D E}\right)$ and average interdemand interval $(p)$ the Croston method is recommended, or in extreme positive cases traditional time series analysis. The proposed method has been generalized recently in the field of information technology (Chovanec and Breznická, 2016; Nikolopoulos et al., 2016; Prestwich et al., 2014).

\section{Extending the existing product forecast classification scheme}

This paper does not aim to develop a new forecasting method for products with sporadic demand, but to test existing forecasting models. The firm analyzed asked us to suggest a complex forecasting strategy for its product portfolio that will result in better forecasting and thus a lower level of inventory accumulation. The core problem of the firm was inventory related, i.e. the excess inventory level of Pharma was estimated at approximately one month of sales. The inventory management practice of Pharma was a typical periodic review system $\left(t_{p}, S\right)$. Parameter $t_{p}$ was measured in weeks (five working days). The maximum inventory level, $S$, was calculated as three weeks' average demand calculated from previous sales data. (This is a built in SAP algorithm.) This calculated $S$ was treated as the forecasted volume for the coming week. This means the actual forecasting (planning) horizon was 1 week. Product managers were permitted to reconsider these data based on their experience, but the suggested forecasts developed by the software were not usually changed. Safety stock levels were not specified. The literature includes a number of results to determine the parameters of inventory holding' mechanisms (Gamberini et al., 2014; Persson et al., 2017).

As pointed out already, the fundamental aim of our empirical investigation was to satisfy a business need, to analyze real life sales data and suggest an appropriate forecasting methodology for Pharma in order to obtain more accurate forecasts and consequently lower inventory level. The company services several hundred pharmacies with more than 10000 product types in a radius of approximately $300 \mathrm{~km}$. The firm in our case study has a centralized distribution structure with 1 main and 6 regional warehouses. All the partner pharmacies in the country place their orders directly with the central warehouse. Based on this demand information, this warehouse plans and directly carries out the distribution of goods in the capital and the central region. Pharmacies in other regions are served by the central warehouse through one of the regional warehouses. Our empirical analysis involved 11924 products traded by the firm. The demand information available covered a period of 97 working days, an almost complete 5 months' period from 03.01.2011 to 20.05.2011. It should be emphasized that this demand information refers to the sum of demand for a concrete product coming into the central warehouse from all the pharmacies, and are not the POS data of the pharmacies themselves.

The first step was to carry out a complete classification of the product portfolio of Pharma. The results are presented in Table 1. After developing this classification, we realized that the literature (see Fig. 1) is incomplete because the developed and suggested scheme is not capable of incorporating products without an existing coefficient of variation (products with only one item of demand data in the analyzed time frame) and products that are without existing zero demand interval. Therefore, we generalized the classification scheme developed by Boylan et al. (2008) and extended its methodology to incorporate all products of the firm including products without any zero demand period and products with only one period with demand.

The number of working days with demand is indicated in Table 1 with $n$, and the number of working days without demand is $m$. Using these characteristics, we grouped the product portfolio into 3 subgroups. The first subgroup

Table 1 Extended classification scheme applied for the complete product portfolio of Pharma

\begin{tabular}{|c|c|c|c|c|c|}
\hline \multirow[b]{2}{*}{ Demar } & \multirow[t]{2}{*}{ Time } & \multirow{2}{*}{$m=0$} & \multicolumn{2}{|c|}{$m \geq 1$} & \multirow{2}{*}{$\begin{array}{c}\text { Number of } \\
\text { products in the } \\
\text { portfolio }\end{array}$} \\
\hline & & & $p<1.32$ & $p \geq 1.32$ & \\
\hline \multirow{2}{*}{$n \geq 2$} & $C V_{D E} \geq 0.7$ & 573 & 1043 & 4124 & 5740 \\
\hline & $C V_{D E}<0.7$ & 1038 & 503 & 4124 & 5665 \\
\hline \multicolumn{2}{|l|}{$n=1$} & 0 & 0 & 519 & 519 \\
\hline \multicolumn{2}{|c|}{$\begin{array}{l}\text { Number of products } \\
\text { in the portfolio }\end{array}$} & 1611 & 1546 & 8762 & 11924 \\
\hline
\end{tabular}


includes products that were demanded, ordered from the central warehouse only once during the whole analyzed timeframe (97 working days). This subgroup was left out from the original classification scheme of Boylan et al. (2008), although from a methodological point of view this is an important subgroup, because the coefficient of demand volume variation cannot be interpreted for these products. Into the other two subgroups were categorized products where this coefficient can be calculated. Differentiation between these latter two subgroups was carried out based on the previously presented suggestion, where the threshold level applied was 0.7 .

The second characteristic of the classification was the average length of interdemand interval $(p)$. When a product was ordered every working day, $p$ could not be interpreted. If a product is not demanded every working day, that means it is not ordered at least one day from the analyzed timeframe. In such cases $p$ can already be calculated and used as a classification criterion. For products where this $p$ could have been calculated, the threshold value of 1.32 suggested by Boylan et al. (2008) was also used in our classification.

As indicated in the Table 1, our extended classification scheme resulted in 1611 products with a regular order pattern, for which there was demand every working day. Of this product category 1038 products had a low demand volume variation, while for 573 products the value of $C V_{D E}$ coefficient indicated a high variation.

It can also be seen that 519 products were ordered only once during the total 97 working days. Any kind of statistical analysis is not applicable for these products. When the length of the timeframe in the analysis is extended, the number of products in this product category is expected to decrease.

5665 products had a low $C V_{D E}$ value. The demand for these products is practically static; 5740 products had a high demand volume variation.

The product categories indicated by bold numbers in Table 1 are those that were used in the classification scheme of Boylan et al. (2008). The product portfolio analyzed includes 503 products with smooth, 4124 with intermittent, 4124 with lumpy and 1043 with erratic demand. In these cases, we were able to test the methodological suggestions developed by Boylan et al. (2008) and Babiloni et al. (2010) and presented above in Fig. 1.

\section{Testing suggested forecast methodologies}

Using the previous demand data provided by Pharma we calculated and present here the forecasted demand for four specific products, representing the four product categories in the classification scheme developed by Boylan et al. (2008) and Babiloni et al. (2010): the smooth, the erratic, the lumpy and the intermittent product categories. The smooth product category is represented by the product Lavestra. The erratic product category is represented by the product called Isodex. The product category with lumpy demand will be exemplified by a product named Menthae. Finally, a product called Isolyte will represent the intermittent product category.

\subsection{A product with smooth demand}

As has just been mentioned, the product category with smooth demand is represented by the Lavestra. This product has a desirably low $C V_{D E}$ value, 0.29 and also a low $p$ value, with 1.0 meaning that the product was regularly ordered almost every working day. The development of demand volumes over time illustrated in Fig. 2 also indicates a smooth demand pattern.

\subsection{A product with erratic demand}

This product category is represented by the product Isodex, which has a relatively high $C V_{D E}$ value of 1.56 . The value of the $p$-index of sporadicity - is 1.1, indicating a low sporadicity of this product. The past demand volumes of the product are shown in Fig. 3.

\subsection{A product with lumpy demand}

Products with lumpy demand are represented by Menthae. It has a $0.99 C V_{D E}$ and a $1.35 p$ value that is slightly above the threshold of 1.32 .

The development of past demand volumes for Menthae are illustrated in Fig. 4. One noteworthy characteristic of this product is that there was demand for it on 70 of the 97 working days examined, which means we were able to identify 27 working days with 0 demand. The demand data also indicate that demand for the product is seasonal; the majority of the demand arises during the winter period. (Because of the relatively low number of observations we had, we assumed a static pattern and did not dealt with the problem of seasonality.)

\subsection{A product with intermittent demand}

The product category with intermittent demand is represented by the product Isolyte. It has a low $C V_{D E}$ value, 0.37 and an extremely high $p$ value of 14.83 , meaning that of the 97 working days examined there was demand for it only every $15^{\text {th }}$ day. During the whole timeframe of our investigation there was demand for it once per day on 6 occasions and twice per day on two occasions. 


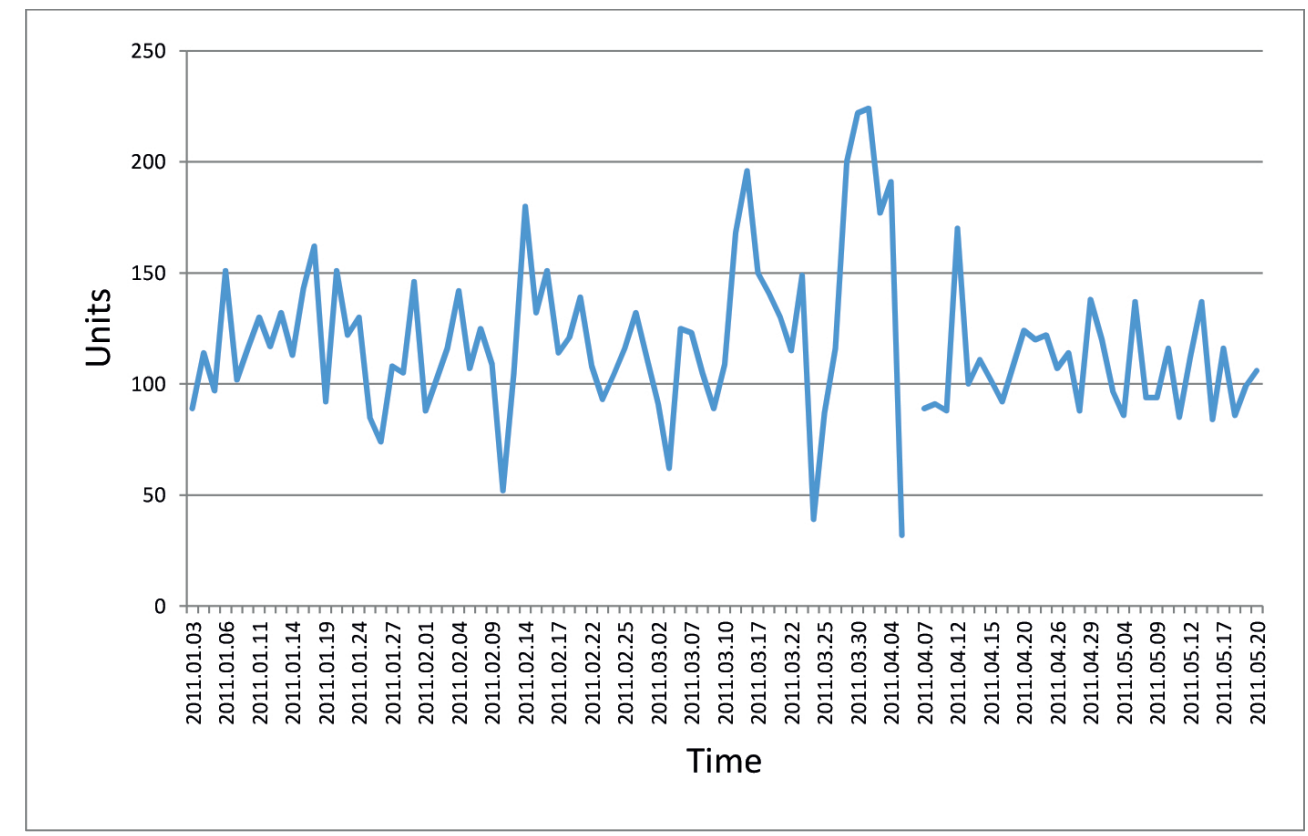

Fig. 2 Demand volumes of Lavestra (using daily data)

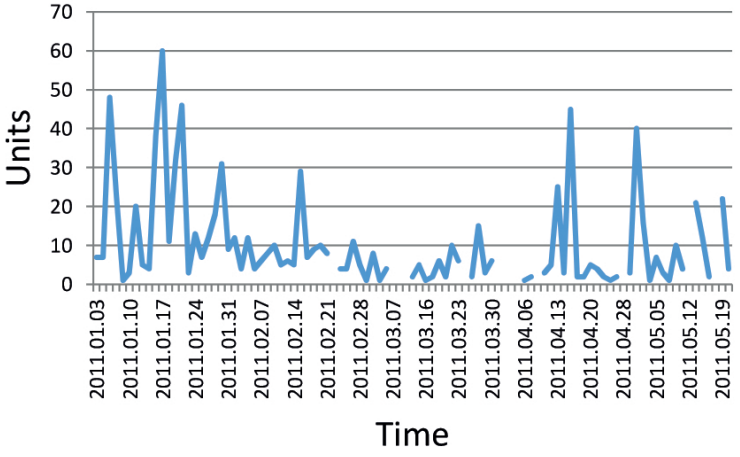

Fig. 3 Demand volumes of Isodex (using daily data)

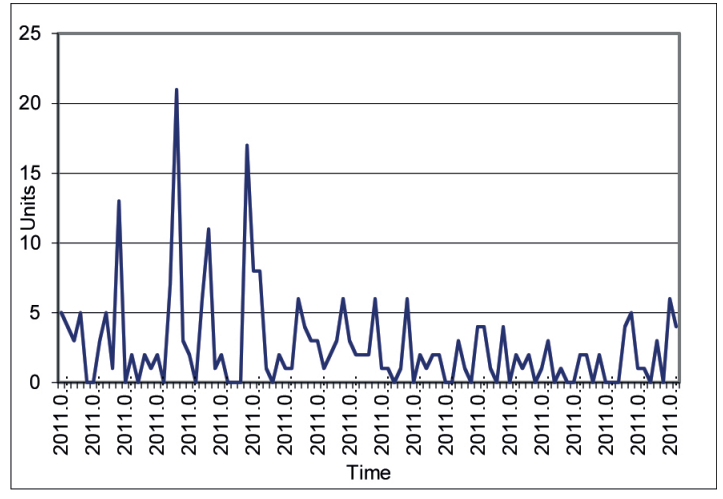

Fig. 4 Demand volumes of Menthae (using daily data)

The development of demand volumes over time for Isolyte are indicated in Fig. 5. It can be seen that there is a relatively low variation in demand volumes but sporadicity is significant.

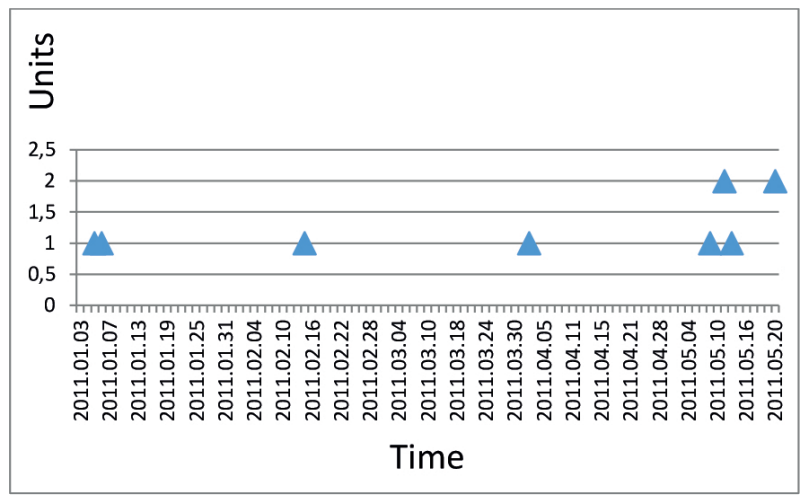

Fig. 5 Demand volumes of Isolyte (using daily data)

Demand forecast is a corrected statistical estimation. Perfect estimation is practically unachievable; therefore, calculating the forecast error is always an essential part of forecasting. Forecast error can be measured in different ways. One broadly used measure (HyndmanKoehler, 2006) is the Mean Absolute Deviation (MAD) that indicates the difference between the forecasted and the actual demand volumes:

$\mathrm{MAD}=\frac{\sum_{i=1}^{n}\left|d_{i}-f_{i}\right|}{n}$,

where $n$ is the number of observations, $d_{i}$ is the actual demand for the product in period $i$, and $f_{i}$ is the forecasted value.

This measure was used in our analysis to evaluate the quality of forecasts which resulted from using different forecast methods. 
Forecasts were made for all four products using 4 different methods as suggested in Fig. 1: moving average and simple exponential smoothing (two classic time series analysis), the Croston and the Syntetos - Boylan method. The results of the test are summarized in Table 2. (The forecast was calculated for 21 May 2011.)

The forecasted volumes with the best MAD values are indicated in the Table 2. For a smooth product, like Lavestra, the suggested forecasting methods are the traditional time series analysis or the Croston method. (In these cases, both the value of $p$ and $C V_{D E}$ are close to their threshold values.) Our test confirms these theoretical suggestions. For the other three product categories (erratic, lumpy and intermittent), the suggested method for forecasting is the Syntetos-Boylan method. Our empirical results back these hypotheses only partially. For our erratic and lumpy product, Isodex and Menthae, the lowest MAD value was obtained using the Syntetos-Boylan method, but for our intermittent product Isolyte a classic time series analysis resulted in the best forecast accuracy.

We extended our empirical test and also calculated the forecasted volumes and their MAD values for additional products with intermittent (Doliva) and lumpy products (Insuman). The results of these new calculations also only partially support the theoretical suggestions for which methodology to apply. In both cases the suggested forecasting methodology would be the Syntetos-Boylan method. Using real life data it was found that, in the case of Doliva, a product with intermittent demand pattern, the lowest MAD value was achieved with simple exponential smoothing and the Croston method. In case of Insuman, a lumpy product, the best forecast was obtained when a moving average was used. To sum up the outcome of the first round of our empirical analysis we can state that our results do not unambiguously support the theoretical suggestions developed by Boylan et al. (2008) and Babiloni et al. (2010).

Table 2 Results of our empirical test (using daily demand data)

\begin{tabular}{lcccc}
\hline $\begin{array}{l}\text { Forecasting } \\
\text { method } \\
\text { applied }\end{array}$ & $\begin{array}{r}\text { Smooth } \\
\text { product: } \\
\text { Lavestra }\end{array}$ & $\begin{array}{c}\text { Erratic } \\
\text { product: } \\
\text { Isodex } \\
\text { Value of MAD }\end{array}$ & $\begin{array}{c}\text { Lumpy } \\
\text { product: } \\
\text { Menthae }\end{array}$ & $\begin{array}{c}\text { Intermittent } \\
\text { product: } \\
\text { Isolyte }\end{array}$ \\
\hline $\begin{array}{l}\text { Moving } \\
\text { average }\end{array}$ & 26.53 & 10.68 & 2.38 & 0.15 \\
$\begin{array}{l}\text { Exponential } \\
\text { smoothing }\end{array}$ & 24.89 & 10.23 & 2.42 & 0.15 \\
$\begin{array}{l}\text { Croston } \\
\text { method }\end{array}$ & 28.16 & 10.42 & 2.61 & 0.20 \\
$\begin{array}{l}\text { Syntetos- } \\
\text { Boylan } \\
\text { method }\end{array}$ & 31.33 & 9.58 & 2.31 & 0.26 \\
\hline
\end{tabular}

\section{Demand data aggregation and its effect} on sporadicity and the quality of forecast

The managers of Pharma indicated that their most important problem was the sporadic character of demand. As mentioned above, applying new forecasting methods (e.g. the Syntetos - Boylan method) for products with sporadic demand gives no straightforward solution to this core problem. As a next potential solution to the problem of sporadicity we tested the impact of demand data aggregation on the quality of forecast (Zotteri et al., 2005).

With the help of a tailor-made Windows Excel macro we were able to specify the number of how many working days out of the total 97 when there was real demand for all the products in Pharma's portfolio; so was also possible to calculate the proportion of days with 0 demand. Based on this information we were able to develop a daily demand curve. As illustrated in Fig. 6 this demand curve is " $\mathrm{U}$ " shaped. On the left side of the curve are those products that can be characterized as having high sporadicity. The proportion of days with 0 demand is very high for these products. The right wing of the curve shows products, where sporadicity is not a problem, the proportion of days with no demand is low, and which are ordered almost every working day.

Similarly, weekly and monthly demand curves can be interpreted by aggregating available daily demand data on weekly and monthly level. Aggregating data also extends the time period of the analyses, in the first step from days to weeks, then from weeks to months. As the length of the period analyzed increases, the number of products with real demand during the given analytical time period will necessarily also increase, while the number of products with 0 demand decreases.

This aggregation was carried out, whereby weekly demand data was worked out using data from 95 working days, since these 95 days make up 19 complete weeks. Of all the 11924 products in the portfolio 23 had

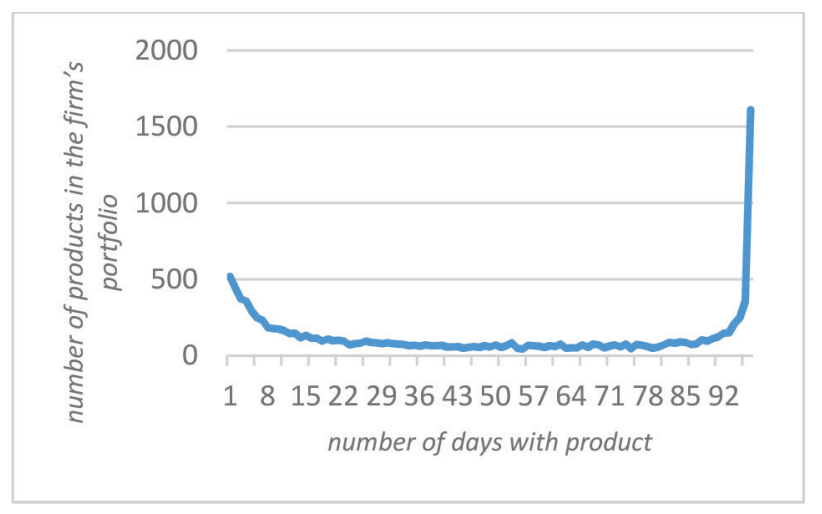

Fig. 6 Daily demand curve of the 11924 products 
demand on the last two days of the analyzed periods. Consequently, these products and their demand data were left out from this step of analysis.

Using daily demand information, we identified 1600 products for which there was actual demand on all 97 working days. Using the aggregated demand information on a weekly basis the number of products for which demand existed during the period analyzed (a week) increased to 4671 .

Monthly or quarterly aggregation can theoretically also be executed. Using demand data aggregated at a monthly level the number of products with demand during the actual analytical period (here month) increased to 7686 , while aggregation on a quarterly basis resulted in 10017 products with real demand during that time period (quarters). Aggregation on these levels, however, may raise serious problems because radically decrease the number of observations available for demand forecasting. As mentioned, we collected information over 97 working days that covered 5 months and 2 quarters. 5 and 2 observations are far from acceptable and no statistical estimation can be based on them.

This also highlights an important managerial implication of such demand data aggregation: Although aggregation can help in smoothing out the sporadic character of products, it can also enormously increase the length of time necessary for forecasting. Where sufficient demand data is available for statistical estimation, the process of aggregation can decrease the sporadic nature of demand and result in a lower $p$ value (index of sporadicity).

As indicated in Fig. 7, aggregating available daily demand data on a weekly and then monthly basis leads to decreased sporadicity indeed. (Slightly grayed boxes indicate the initial data sets.) Previously we discussed

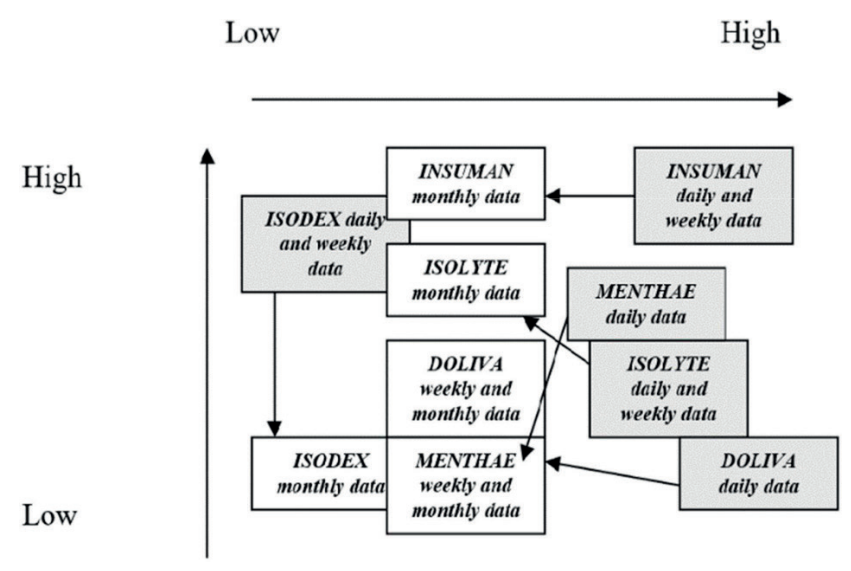

Fig. 7 Changing demand character of the analyzed products due to demand data aggregation the case of $4+2$ products. For all 6 of these products we calculated the actual $C V_{D E}$ and $p$ values for aggregated both weekly and monthly data. The results of these calculations are summarized in Table 3. Aggregating daily demand data manually always resulted in lower sporadicity although in some cases (see product Isolyte) aggregation led to increased demand volume variation.

Our practical objective was to help Pharma to develop more reliable forecasting and a more efficient inventory management system. To be able to do that we wanted to test methodological recommendations published in the literature for products with sporadic demand character. Therefore, we calculated the actual forecast values for several particular products using not only the initial raw dataset of daily demand information, but also using aggregated weekly demand data. Due to the very low number of observations (from 2 to 5) the demand data aggregated on a monthly level were not used for further forecasting. A summary of our calculations is presented in Table 4.

In Table 4 we have bolded the forecast methods, which were actually in line with theoretical suggestions. Where forecasts were carried out using daily demand data the theoretical suggestions could be confirmed in only 3 cases of the 6 (Lavestra, Isodex and Menthae). After aggregating the daily data at the weekly level and using this aggregated database for forecasting, the number of products for which the suggested methodology was confirmed increased to 5. Only in case of the product Insuman did the theoretical suggestion not match our empirical result.

When classification is carried out using monthly aggregated data, Insuman's product classification changes from lumpy to erratic. This indicates that using very long time series data may help solve the problem of forecasting. Insuman represents the most problematic product category, the lumpy product. Of the 11924 products Pharma has in its product portfolio 4124 belong to this category.

\section{Conclusions and further research}

This paper investigated a forecasting system for a wholesale pharmaceutical firm. We analyzed its sales data and developed a classification scheme for its product portfolio based on the two relevant demand characteristics, using the coefficient of variance and the average interdemand interval of products. This scheme is an extended version of the suggested demand classification scheme suggested by Boylan et al. (2008) and Babiloni et al. (2010). Our extended classification scheme includes also products that were without an existing coefficient of variation, 
Table 3 Demand typology based on initial daily, aggregated weekly and monthly data

\begin{tabular}{|c|c|c|c|c|c|c|}
\hline \multirow{2}{*}{$\begin{array}{l}\text { Product } \\
\text { characteristics }\end{array}$} & Demand type & $\begin{array}{l}\text { No. of data with demand } \\
\text { (proportion to the total) }\end{array}$ & Demand type & $\begin{array}{l}\text { No. of data with demand } \\
\text { (proportion to the total) }\end{array}$ & Demand type & $\begin{array}{l}\text { No. of data with demand } \\
\text { (proportion to the total) }\end{array}$ \\
\hline & \multicolumn{2}{|r|}{ Daily } & \multicolumn{2}{|r|}{ Weekly } & \multicolumn{2}{|r|}{ Monthly } \\
\hline LAVESTRA & $\begin{array}{c}\text { Smooth } \\
C V=0.29 \\
p=1\end{array}$ & $\begin{array}{c}96 \\
98.96 \%\end{array}$ & $\begin{array}{c}\text { Smooth } \\
C V=0.16, \\
p=\text { not exist }\end{array}$ & $\begin{array}{c}19 \\
100 \%\end{array}$ & $\begin{array}{c}\text { Smooth } \\
C V=0.2 \\
p=\text { not exist }\end{array}$ & $\begin{array}{c}5 \\
100 \%\end{array}$ \\
\hline ISODEX & $\begin{array}{c}\text { Erratic } \\
C V=1.56 \\
p=1.1\end{array}$ & $\begin{array}{c}86 \\
88.66 \%\end{array}$ & $\begin{array}{c}\text { Erratic } \\
C V=0.8 \\
p=\text { not exist }\end{array}$ & $\begin{array}{c}19 \\
100 \%\end{array}$ & $\begin{array}{c}\text { Smooth } \\
C V=0.56 \\
p=\text { not exist }\end{array}$ & $\begin{array}{c}5 \\
100 \%\end{array}$ \\
\hline ISOLYTE & $\begin{array}{l}\text { Intermittent } \\
C V=0.37 \\
p=14.83\end{array}$ & $\begin{array}{c}8 \\
8.25 \%\end{array}$ & $\begin{array}{l}\text { Intermittent } \\
C V=0.56 \\
p=4.56\end{array}$ & $\begin{array}{c}5 \\
26.32 \%\end{array}$ & $\begin{array}{c}\text { Erratic } \\
C V=1.17 \\
p=1\end{array}$ & $\begin{array}{c}4 \\
80 \%\end{array}$ \\
\hline DOLIVA & $\begin{array}{l}\text { Intermittent } \\
\begin{array}{c}C V=1.46 \\
p=2\end{array}\end{array}$ & $\begin{array}{c}46 \\
47.42 \%\end{array}$ & $\begin{array}{c}\text { Smooth } \\
C V=0.58 \\
p=\text { not exist }\end{array}$ & $\begin{array}{c}19 \\
100 \%\end{array}$ & $\begin{array}{c}\text { Smooth } \\
C V=0.39 \\
p=\text { not exist }\end{array}$ & $\begin{array}{c}5 \\
100 \%\end{array}$ \\
\hline INSUMAN & $\begin{array}{c}\text { Lumpy } \\
C V=2.88 \\
p=16.66\end{array}$ & $\begin{array}{c}14 \\
14.43 \%\end{array}$ & $\begin{array}{l}\text { Lumpy } \\
C V=1.44 \\
p=7.5\end{array}$ & $\begin{array}{c}4 \\
21.05 \%\end{array}$ & $\begin{array}{c}\text { Erratic } \\
C V=1.83, \\
p=3\end{array}$ & $\begin{array}{c}2 \\
40 \%\end{array}$ \\
\hline MENTHAE & $\begin{array}{c}\text { Lumpy } \\
C V=1.32 \\
p=1.35\end{array}$ & $\begin{array}{c}70 \\
72.16 \%\end{array}$ & $\begin{array}{c}\text { Smooth } \\
C V=0.61, \\
p=\text { not exist }\end{array}$ & $\begin{array}{c}19 \\
100 \%\end{array}$ & $\begin{array}{c}\text { Smooth } \\
C V=0.48, \\
p=\text { not exist }\end{array}$ & $\begin{array}{c}5 \\
100 \%\end{array}$ \\
\hline
\end{tabular}

Table 4 Results of or empirical test using daily and aggregated weekly demand data

\begin{tabular}{|c|c|c|c|c|}
\hline & Product category & $\begin{array}{l}\text { Method resulting in lowest MAD value } \\
\text { daily data }\end{array}$ & Product category using & $\begin{array}{l}\text { Method resulting in lowest MAD value } \\
\text { weekly data }\end{array}$ \\
\hline LAVESTRA & Smooth & Exponential smoothing & Smooth & Exponential smoothing \\
\hline ISODEX & Erratic & Syntetos-Boylan & Erratic & Syntetos-Boylan \\
\hline ISOLYTE & Intermittent & $\begin{array}{l}\text { Moving average, } \\
\text { Exponential smoothing }\end{array}$ & Intermittent & Syntetos-Boylan \\
\hline MENTHAE & Lumpy & Syntetos-Boylan & Smooth & Moving average \\
\hline DOLIVA & Intermittent & $\begin{array}{l}\text { Croston, } \\
\text { Exponential smoothing }\end{array}$ & Smooth & Exponential smoothing \\
\hline INSUMAN & Lumpy & Moving average & Lumpy & Moving average \\
\hline
\end{tabular}

i.e. only one piece of demand data is available in the analyzed time frame. This scheme also makes it possible to classify products that do not have a zero demand interval. Using this scheme all items in a concrete product portfolio can be classified.

After the classification we tested the forecasting methods that are suggested by state-of-the-art literature. Our empirical analysis only partly supported these recommendations; in 3 cases of the 6 analyzed these recommendations hold. The next step was to aggregate the initial daily demand data provided by Pharma. The basic aim of this aggregation was to decrease the sporadicity of products. The results supported our hypothesis, and the sporadicity index of all the analyzed products decreased. Aggregation was carried out both on weekly and monthly bases. After aggregation we tested the proposed forecasting method again. The results show that the reliability of theoretical suggestions increased, so that for 5 of the 6 products the 6 suggested forecasting method resulted in the lowest MAD value.

This result has important managerial relevance, since it can result in better forecasting and lead to more efficient inventory management. Managers should be aware of the relatively easy technical solution of data aggregation and consider its potential when developing firm-specific forecasting and inventory management systems. This data aggregation aims to specify the length of the forecast period, where the sporadicity index hits the threshold level. However, we also have to highlight the prerequisite of such an aggregation. We noticed that in some of our product examples even quarterly or yearly aggregation would have been necessary to effectively reduce the index of sporadicity. This underlines the importance of developing appropriately long databases for effective forecasting. 
The adequate forecast period determined with the help of aggregation also influences the suggested inventory management policy. The forecast period proposed using such a data aggregation should affect not only the length of review of the actual inventory information, but also the necessary safety stock level. Specifically, we recommended that Pharma apply the concept of a reorder point and introduce a mixed inventory policy $\left(t_{p}, s, S\right)$, where the period length specified in aggregation determines the volume of safety stock.

Besides the managerial relevance of our analysis, the suggested technique of data aggregation also raises theoretical questions. The aggregation has crucial mathematical statistical consequences. We did not examine how such an aggregation would change the statistical properties of a time series; such as the distribution or density

\section{References}

Babiloni, E., Cardós, M., Albarracín, J. M., Palmer, M. E. (2010) "Demand Categorization, Forecasting, and Inventory Control for Intermittent Demand Items", South African Journal of Industrial Engineering, 21(2), pp. 115-130. [online] Available at: http://www.scielo.org.za/ pdf/sajie/v21n2/11.pdf [Accessed: 23 April 2017]

Boylan, J. E., Syntetos, A. A., Karakostas, G. C. (2008) "Classification for forecasting and stock control: A case study", Journal of the Operational Research Society, 59(4), pp. 473-481. https://doi.org/10.1057/palgrave.jors.2602312

Chitturi, P., Gershon, M., Chen, J., Boyarski, J. (2010) "Identification and classification of intermittent demand patterns", International Journal of Productivity and Quality Management, 6(3), pp. 304-317. https://doi.org/10.1504/IJPQM.2010.035118

Chovanec, A., Breznická, A. (2016) "Simulation Modelling Of A Sporadic Demand Applying A Bootstraping", Reliability: Theory \& Applications, 11(4), pp. 49-54. [online] Available at: https://cyberleninka.ru/article/n/simulation-modelling-of-a-sporadic-demand-applying-a-bootstraping [Accessed: 25 May 2017]

Croston, J. D. (1972) "Forecasting and Stock Control for Intermittent Demand", Journal of the Operational Research Society, 23(3), pp. 289-303.

https://doi.org/10.1057/jors.1972.50

Eaves, A. H. C., Kingsman, B. G. (2004) "Forecasting for the ordering and stock-holding of spare parts", Journal of the Operational Research Society, 55(4), pp. 431-437. https://doi.org/10.1057/palgrave.jors.2601697

Gamberini, R., Lolli, F., Regattieri, A., Rimini, B. (2014) "Dynamic Re-order Policies for Irregular and Sporadic Demand Profiles", Procedia Engineering, 69, pp. 1420-1429. https://doi.org/10.1016/j.proeng.2014.03.137

Hyndman, R. J., Koehler, A. B. (2006) "Another look at measures of forecast accuracy", International Journal of Forecasting, 22(4), pp. 679-688.

https://doi.org/10.1016/j.ijforecast.2006.03.001 function of the derived demand data set, which may directly influence the main inventory related information, such as lot size for example. The clarification of these theoretical issues needs further research, and can contribute to more generalizable recommendations.

The suggested forecast horizon could also have a crucial influence on the inventory management. First, the proposed forecast period determines the length of periodic review, in our case the magnitude of parameter $t_{p}$. Secondly, this period length affects the volume of the safety stock, i.e. the safety stock must cover the excess demand on the forecast horizon $t_{p}$ (Novotna and Sustrova, 2018).

\section{Acknowledgements}

The authors thank for the support of NKFIH K 115542.

Jónás, T., Árva, G., Tóth, Z. E. (2018) "Forecasting Failure Rates of Electronic Goods by Using Decomposition and Fuzzy Clustering of Empirical Failure Rate Curves", Periodica Polytechnica Social and Management Sciences, 26(1), pp. 10-18. https://doi.org/10.3311/PPso.9026

Kourentzes, N. (2014) "On intermittent demand model optimisation and selection", International Journal of Production Economics, 156, pp. $180-190$. https://doi.org/10.1016/j.ijpe.2014.06.007

Nikolopoulos, K. I., Babai, M. Z., Bozos, K. (2016) "Forecasting supply chain sporadic demand with nearest neighbor approaches", International Journal of Production Economics, 177, pp. 139-148. https://doi.org/10.1016/j.ijpe.2016.04.013

Novotna, V., Sustrova, T. (2018) "Order Management System Proposal Using Inventory Balance Equation with Non-continuous Replenishment", Periodica Polytechnica Social and Management Sciences, 26(1), pp. 1-9. https://doi.org/10.3311/PPso.9017

Pennings, C. L. P., van Dalen, J., van der Laan, E. A. (2017) "Exploiting elapsed time for managing intermittent demand for spare parts", European Journal of Operational Research, 258(3), pp. 958-969. https://doi.org/10.1016/j.ejor.2016.09.017

Persson, F., Axelsson, M., Edlund, F., Lanshed, C., Lindström, A., Persson, F. (2017) "Using Simulation to Determine the Safety Stock Level for Intermittent Demand", In: Chan, W. K. V., D’Ambrogio, A., Zacharewicz, G., Mustafee, N., Wainer, G., Page, E. (eds.) Proceedings of the 2017 Winter Simulation Conference, IEEE Press, New York, USA, pp. 3768-3779. [online] Available at: http://simulation.su/uploads/files/default/2017-persson-axelsson-edlund-lanshed-lindstrom-persson.pdf [Accessed: 13 June 2017]

Peterson, R., Silver, E. A. (1985) "Decision Systems for Inventory Management and Production Planning", Wiley, New York, USA. 
Petropoulos, F., Kourentzes, N. (2015) "Forecast combinations for intermittent demand", Journal of the Operational Research Society, 66(6), pp. 914-924.

https://doi.org/10.1057/jors.2014.62

Prestwich, S. D., Tarim, S. A., Rossi, R., Hnich, B. (2014) "Forecasting intermittent demand by hyperbolic-exponential smoothing", International Journal of Forecasting, 30(4), pp. 928-933. https://doi.org/10.1016/j.ijforecast.2014.01.006

Syntetos, A. A., Boylan, J. E. (2001) "On the bias of intermittent demand estimates", International Journal of Production Economics, 71(1-3), pp. $457-466$.

https://doi.org/10.1016/S0925-5273(00)00143-2

Syntetos, A. A., Boylan, J. E., Croston, J. D. (2005) "On the categorization of demand patterns", Journal of the Operational Research Society, 56(5), pp. 495-503.

https://doi.org/10.1057/palgrave.jors.2601841
Vasumathi, B., Saradha, A. (2014) "Forecasting of Sporadic Demand Patterns with Spare Parts", International Journal of Innovation and Applied Studies, 8(1), pp. 237-242. [online] Available at: ht t p://citeseerx.ist.psu.edu/viewdoc/download? doi=10.1.1.671.280\&rep=rep1\&type=pdf [Accessed: 13 June 2017]

Vollmann, Th., E., Berry, W. L., Whybark, D. C. (1984) "Manufacturing Planning and Control Systems", Dow Jones-Irwin, Homewood, IL, USA.

Zotteri, G., Kalchschmidt, M., Caniato, F. (2005) "The impact of aggregation level on forecasting performance", International Journal of Production Economics, 93-94, pp. 479-491.

https://doi.org/10.1016/j.ijpe.2004.06.044 